\title{
CD73: A Promising Biomarker in Cancer Patients
}

\author{
Roberta Turiello, Aldo Pinto and Silvana Morello* \\ Department of Pharmacy, University of Salerno, Fisciano, Italy
}

Keywords: CD73, adenosine, immunotherapy, cancer, biomarker

\section{INTRODUCTION}

Over the past years, the adenosine pathway has become a topic of great interest in cancer research, due to an increasing number of evidences showing its role in tumor progression and metastases. Within tumor microenvironment, extracellular adenosine reaches elevated concentrations and by activating the adenosine receptor subtypes $\mathrm{A} 2 \mathrm{~A}$ and $\mathrm{A} 2 \mathrm{~B}$ limits the effector $\mathrm{T}$ cell functions, induces immunosuppression, and stimulates angiogenesis (recently reviewed in Allard et al., 2020). Extracellular adenosine production is finely regulated by many enzymes (Yegutkin, 2008), and it is critically impaired in pathological conditions, such as inflammatory disorders or cancer (Allard et al., 2020). The classical pathway of extracellular adenosine production is based on sequential reactions mediated by two ectonucleotidases, specifically extracellular adenosine triphosphate is first hydrolyzed by CD39 into adenosine monophosphate (AMP) and then dephosphorylated into adenosine by CD73. The alternative pathway involves CD38 and CD203a, which convert $\mathrm{NAD}^{+}$ into ADP-ribose and ADP-ribose into AMP, respectively (Horenstein et al., 2013). AMP is, in turn, dephosphorylated into adenosine by CD73. In this context, CD73 has aroused particular interest, being the key enzyme in extracellular adenosine production, both in classical and alternative pathways. CD73 is a dimeric enzyme that exists in two forms: one form is anchored, via glycosylphosphatidylinositol, to the membrane of many cells or extracellular vesicles; the second form is generated upon cleavage from membranes through the action of proteases or phospholipases, and it is found in biological fluids (Zimmermann et al., 2012).

A large number of preclinical studies have investigated the role of CD73 in immunosuppression and tumor progression, proving that the inhibition of CD73 is an effective immunotherapeutic strategy for different types of cancers. Agents targeting CD73, including monoclonal antibodies and small molecules, have been developed and are undergoing clinical trials, alone or in combination with other immune checkpoint inhibitors (Allard et al., 2020; Thompson and Powell, 2020). New CD73 inhibitors have proved to be effective in controlling tumor growth and immune response in preclinical studies and would warrant clinical investigations (Jin et al., 2020; Schäkel et al., 2020).

To date, various studies have also explored the significance of CD73 expression and activity in cancer patients, evaluating possible correlations with survival and/or clinical response. Here, we discuss the relevance of different forms of CD73 as prognostic biomarker of tumor progression in cancer patients or as predictive biomarker of response to anticancer therapies.

\section{MEMBRANE-BOUND CD73 IN CANCER PATIENTS}

In cancer, CD73 is expressed by many subsets of cells populating the tumor lesion, including tumor cells, stromal cells, and endothelial cells, as well as infiltrating immune cells (Vijayan et al., 2017). High CD73 tumor expression is associated with shorter overall survival and poor prognosis of patients with melanoma (Monteiro et al., 2018), diffuse large B-cell lymphoma (Wang et al., 2019), breast cancer (Loi et al., 2013; Turcotte et al., 2017; Buisseret et al., 2018; Jiang et al., 2018), ovarian 
cancer (Turcotte et al., 2015; Jiang et al., 2018), head and neck cancer (Mandapathil et al., 2018), head and neck squamous carcinoma (Ren et al., 2016) non-small-cell lung cancer (Inoue et al., 2017), thyroid carcinoma (Bertoni et al., 2019), pancreatic cancer (Chen et al., 2020), gastric cancer (Lu et al., 2013), or colorectal cancer (Wu et al., 2012). Of note, the upregulation of $\mathrm{CD} 73$ in cancer patients has been addressed as a mechanism of resistance to antitumor therapies. Loi and coworkers observed that CD73 gene expression significantly related to poor prognosis in triple-negative breast cancer patients treated with anthracycline-only preoperative chemotherapy (Loi et al., 2013). In the same study, in a breast cancer mouse model, the authors demonstrated that CD73 overexpression on tumor cells determines chemoresistance to anthracycline treatment, while the blockade of the enzyme improved antitumor immune response (Loi et al., 2013). In another study, CD73 expression associated with poor outcome of breast cancer patients treated with trastuzumab, an anti-HER2/ ErbB2 antibody, while its expression on tumor cells and host cells was linked to resistance to monoclonal antibody treatment in a mouse model of HER2/ErbB2-driven breast cancer (Turcotte et al., 2017). Interestingly, a dynamic regulation of CD73 expression was hypothesized as an acquired mechanism of resistance to immunotherapy by Reinhardt and colleagues, who reported that melanoma patients who showed progressive disease during anti-PD-1 therapy had also increased CD73 expression in tumor tissue (Reinhardt et al., 2017). Patients who had prior therapy with inhibitors of MAPK and BRAF were negative for CD73 expression, while patients who had not received MAPK inhibitor therapy showed CD73 upregulation at progression (Reinhardt et al., 2017). Although these results were obtained in a small number of patients and further investigations are required, they suggest that the tumor expression of CD73 may change on treatment.

Opposite results were obtained in bladder cancer patients, in whom low CD73 expression associated with better survival (Wettstein et al., 2015; Koivisto et al., 2018). Although results by Koivisto and collaborators were obtained from a single retrospective study, they are of great interest underlining the importance to analyze the CD73 expression in each cell types within the tumor microenvironment. CD73 negative epithelial cells significantly associated with poor survival both in patients with non-muscle-invasive bladder cancer and muscle-invasive bladder cancer, while CD73 expression in stromal fibroblasts or lymphocytes had no predictive power (Koivisto et al., 2018). As the authors suggest, these results may be due to the role of endothelial CD73 in controlling the permeability of the blood vessels and the extravasation of leukocytes. However, in prostate cancer, Leclerc and coworkers observed that high levels of CD73 in normal adjacent prostate epithelium were significantly associated with shorter biochemical recurrence-free survival, while high levels of CD73 in the tumor stroma were associated with longer biochemical recurrence-free survival (Leclerc et al., 2016). In endometrial carcinoma, CD73 is down-regulated in carcinoma cells of poorly differentiated and advanced-stage disease, compared with normal endometrium and low-grade tumors, highlighting the protective function of
CD73-derived adenosine on epithelial integrity in normal endometrium (Bowser et al., 2016). Thus, the loss of CD73 on epithelial cells may promote the tumor progression. Additional evidence on the controversial role of CD73 were given by Wang and coworkers, who observed that the lower expression of CD73 in blood vessels of glioma patients than in normal brain may cause damage to the blood-brain barrier, thus creating advantageous conditions for tumor growth (Wang et al., 2016).

In a very recent work, it has been observed that CD73 is highly expressed on cancer-associated fibroblasts in human colorectal cancers, and high CAF frequency in cancer tissues correlates with elevated CD73 activity and poor prognosis (Yu et al., 2020). In patients with glioblastoma multiforme undergoing anti-PD-1 treatment, Goswami and colleagues individuated the presence of $\mathrm{CD} 73^{\text {hi }}$ immunosuppressive myeloid cell subsets, which may cause less $\mathrm{T}$-cell infiltration in tumor microenvironment (Goswami et al., 2020). In sarcoma and breast cancer, tumorinfiltrating NK cells express high level of CD73, and the frequency of $\mathrm{CD} 3^{+} \mathrm{NK}$ cells in the tumor microenvironment correlates with larger tumor size in patients with breast cancer (Neo et al., 2020).

CD73 is expressed not only on cell populations composing the tumor microenvironment but also on circulating immune cells. High baseline percentage of circulating $\mathrm{CD} 8^{+} \mathrm{PD}-1^{+} \mathrm{CD} 73^{+}$ lymphocytes correlate with worse survival in malignant melanoma patients treated with nivolumab (Capone et al., 2020).

\section{SOLUBLE CD73 IN CANCER PATIENTS}

Since a soluble form of human CD73 was identified (Thompson et al., 1987; Coade and Pearson, 1989), many studies were settled to understand the role of this form in inflammatory and tumor processes. In 1989, Lal and colleagues reported that CD73 expression in serum of head and neck cancer patients was higher than that in healthy subjects (Lal et al., 1989). Interestingly, the enzymatic activity increased with the advancement in the stage of cancer (Lal et al., 1989). Of note, Lehto and Sharom in 1998 observed that the soluble form of CD73 is enzymatically more active than the membrane-bound variant (Lehto and Sharom, 1998). Nowadays, a great number of publications state that soluble CD73 expression and activity are increased in several human cancers (Huang et al., 2015; Morello et al., 2017; De Lourdes Mora-García et al., 2019; Gardani et al., 2019). All these evidence constitute the rationale for new interesting studies aimed to clarify whether CD73 could be used as a soluble biomarker in cancer patients. At this regard, in 2017, we found that CD73 activity in serum of melanoma patients correlates with overall survival, progression-free survival, and clinical response to nivolumab treatment (Morello et al., 2017). Very recently, Messaoudi and collaborators observed that patients with colorectal cancer liver metastases who had high levels of soluble CD73 had also shorter survival (Messaoudi et al., 2020). In the same study, expression of tumor CD73 is a stronger biomarker than the soluble form.

Soluble CD73 in plasma of metastatic breast cancer patients tends to increase after radiotherapy treatment, while its blockade 
reduces the irradiated tumor volume and, if combined with CTLA-4 blockade, inhibits lung metastases in a mice model (Wennerberg et al., 2020).

\section{CD73 ON EXTRACELLULAR VESICLES}

The circulating portion of non-cell-bound CD73 also includes extracellular vesicles, and in particular, exosomes $(30-150 \mathrm{~nm})$ that can be produced by almost all cells, including cancer cells (Becker et al., 2016; Théry et al., 2018). The published studies focused on soluble CD73 in human fluids do not consider these vesicles, so it is still unclear whether the soluble CD73 expression and/or activity is influenced by the exosomal form. To date, no studies considering both the shedded and the exosomal forms have been published, and this represents a very interesting point to investigate on.

CD73 has been detected on human exosomes isolated from plasma and serum (Muller et al., 2014; Schuler et al., 2014; Theodoraki et al., 2018) and pleural fluid (Clayton et al., 2011). Notably, CD73 expressed on exosomes maintains its enzymatic activity, and the exosome-derived adenosine is responsible of $\mathrm{T}$-cell inhibition and impaired antitumor immune response (Clayton et al., 2011; Schuler et al., 2014; Ludwig et al., 2017; Zhang et al., 2019). Expression of CD73 and CD39 on exosomes isolated from plasma of HNSCC patients related with the stage of disease, being higher in stage III/IV than stage I/II (Theodoraki et al., 2018).

Exosomes isolated from UMSCC47 cell lines are not only able to produce adenosine, via CD39 and CD73, but also carry adenosine and inosine in their inner compartment (Ludwig et al., 2020). Thus, exosomes can circulate in body fluids and can promote a tumorigenic environment by producing adenosine in loco, via CD39 and CD73, and also by transporting and releasing adenosine and inosine far from the site where they are released, protecting these molecules from metabolism or uptake processes (Ludwig et al., 2020). This could be one of the mechanisms by which exosomes promote tumor growth and metastases dissemination.

\section{REFERENCES}

Allard, B., Allard, D., Buisseret, L., and Stagg, J. (2020). The adenosine pathway in immuno-oncology. Nat. Rev. Clin. Oncol. 17, 611-629. doi:10.1038/s41571020-0382-2

Becker, A., Thakur, B. K., Weiss, J. M., Kim, H. S., Peinado, H., and Lyden, D. (2016). Extracellular vesicles in cancer: cell-to-cell mediators of metastasis. Cancer Cell 30, 836-848. doi:10.1016/j.ccell.2016.10.009

Bertoni, A. P. S., Bracco, P. A., De Campos, R. P., Lutz, B. S., Assis-Brasil, B. M., Meyer, E. L. d. S., et al. (2019). Activity of ecto-5' -nucleotidase (NT5E/CD73) is increased in papillary thyroid carcinoma and its expression is associated with metastatic lymph nodes. Mol. Cell. Endocrinol. 479, 54-60. doi:10.1016/j.mce.2018.08.013

Bowser, J. L., Blackburn, M. R., Shipley, G. L., Molina, J. G., Dunner, K., Jr., and Broaddus, R. R. (2016). Loss of CD73-mediated actin polymerization promotes endometrial tumor progression. J. Clin. Invest. 126, 220-238. doi:10.1172/ JCI79380

\section{CONCLUSION AND FUTURE PERSPECTIVES}

The purinergic signaling plays a critical role in cancer, since adenosine triphosphate is released in the tumor microenvironment upon hypoxia, nutrient starvation, cell death, or treatment with some chemotherapeutic agents. It is well known that adenosine triphosphate acts as proinflammatory mediator; nevertheless, the high expression of CD39 and CD73 in tumor microenvironment enhances its conversion into adenosine, which, in turn, is responsible for tumor growth and impaired immune response (Sorrentino et al., 2013).

Many components of the adenosine pathway have been assessed as a therapeutic target or potential biomarker of prognosis. In particular, CD73 has emerged as a promising candidate both as a target and biomarker in different human tumors, as mentioned above, helpful in clinical practice to select patients that would likely respond to CD73-targeted therapy. Many studies focusing on the expression of CD73 in tumor tissue have been published; nevertheless, it has to be noted that results may be different according to the tissue type and its heterogeneity, or to the technics used to measure the expression. Furthermore, the possible effect of pharmacological treatments on CD73 expression needs to be considered. The analysis on tumor tissue is an invasive and painful procedure that could be particularly difficult in patients with metastatic disease. The analysis of the soluble CD73 in biological fluids, which needs further investigations, could represent an additional tool in clinical practice.

To date, further investigations are required to better understand the role of $\mathrm{CD}^{+} 3^{+}$exosomes in cancer, evaluating the possibility to use these vesicles as biomarkers of prognosis. One more point that needs to be explored is the mechanism regulating the cleavage of CD73 from the cell membrane. It could be of great interest to fully understand the stimuli that promote the shedding and/or the production of $\mathrm{CD}^{+} 3^{+}$exosomes, evaluating whether the blockade of these processes could impact tumor progression.

\section{AUTHOR CONTRIBUTIONS}

RT and SM conceived the manuscript. RT, AP, and SM drafted and reviewed the manuscript.

Buisseret, L., Pommey, S., Allard, B., Garaud, S., Bergeron, M., Cousineau, I., et al. (2018). Clinical significance of CD73 in triple-negative breast cancer: multiplex analysis of a phase III clinical trial. Ann. Oncol. 29, 1056-1062. doi:10.1093/ annonc/mdx730

Capone, M., Fratangelo, F., Giannarelli, D., Sorrentino, C., Turiello, R., Zanotta, S., et al. (2020). Frequency of circulating $\mathrm{CD} 8^{+} \mathrm{CD} 73^{+} \mathrm{T}$ cells is associated with survival in nivolumab-treated melanoma patients. J. Transl. Med. 18, 121 doi:10.1186/s12967-020-02285-0

Chen, Q., Pu, N., Yin, H., Zhang, J., Zhao, G., Lou, W., et al. (2020). CD73 acts as a prognostic biomarker and promotes progression and immune escape in pancreatic cancer. J. Cell Mol. Med. 24 (15), 8674-8686. doi:10.1111/jcmm. 15500

Clayton, A., Al-Taei, S., Webber, J., Mason, M. D., and Tabi, Z. (2011). Cancer exosomes express CD39 and CD73, which suppress T cells through adenosine production. J. Immunol. 187, 676-683. doi:10.4049/jimmunol.1003884

Coade, S. B., and Pearson, J. D. (1989). Metabolism of adenine nucleotides in human blood, Circ. Res. 65, 531-537. doi:10.1161/01.res.65.3.531 
De Lourdes Mora-García, M., López-Cisneros, S., Gutiérrez-Serrano, V., GarcíaRocha, R., Weiss-Steider, B., Hernández-Montes, J., et al. (2019). HPV-16 infection is associated with a high content of CD39 and CD73 ectonucleotidases in cervical samples from patients with CIN-1. Mediat. Inflamm. 2019, 4651627. doi:10.1155/2019/4651627

Gardani, C. F. F., Cappellari, A. R., De Souza, J. B., Da Silva, B. T., Engroff, P., Moritz, C. E. J., et al. (2019). Hydrolysis of ATP, ADP, and AMP is increased in blood plasma of prostate cancer patients. Purinergic Signal. 15, 95-105. doi:10. 1007/s11302-018-9642-3

Goswami, S., Walle, T., Cornish, A. E., Basu, S., Anandhan, S., Fernandez, I., et al. (2020). Immune profiling of human tumors identifies CD73 as a combinatorial target in glioblastoma. Nat. Med. 26, 39-46. doi:10.1007/s11302-018-9642-3

Horenstein, A. L., Chillemi, A., Zaccarello, G., Bruzzone, S., Quarona, V., Zito, A., et al. (2013). A CD38/CD203a/CD73 ectoenzymatic pathway independent of CD39 drives a novel adenosinergic loop in human $\mathrm{T}$ lymphocytes. Oncoimmunology 2, e26246. doi:10.4161/onci.26246

Huang, Q., Durham, N. M., Sult, E., Wu, Y., Liu, J., Holoweckyj, N., et al. (2015). Abstract 1538: levels and enzyme activity of CD73 in primary samples from cancer patients. Cancer Res. 75, 1538. doi:10.1158/1538-7445.am2015-1538

Inoue, Y., Yoshimura, K., Kurabe, N., Kahyo, T., Kawase, A., Tanahashi, M., et al. (2017). Prognostic impact of CD73 and A2A adenosine receptor expression in non-small-cell lung cancer. Oncotarget 8, 8738-8751. doi:10.18632/oncotarget. 14434

Jiang, T., Xu, X., Qiao, M., Li, X., Zhao, C., Zhou, F., et al. (2018). Comprehensive evaluation of NT5E/CD73 expression and its prognostic significance in distinct types of cancers. BMC Cancer 18, 267. doi:10.1186/s12885-018-4073-7

Jin, R., Liu, L., Xing, Y., Meng, T., Ma, L., Pei, J., et al. (2020). Dual mechanisms of novel CD73-targeted antibody and antibody-drug conjugate in inhibiting lung tumor growth and promoting antitumor immune-effector function. Mol. Cancer Therapeut. [Epub ahead of print]. doi:10.1158/1535-7163.mct-20007632943546

Koivisto, M. K., Tervahartiala, M., Kenessey, I., Jalkanen, S., Boström, P. J., and Salmi, M. (2018). Cell-type-specific CD73 expression is an independent prognostic factor in bladder cancer. Carcinogenesis 40, 84-92. doi:10.1093/ carcin/bgy15430395172

Lal, H., Kumar, L., Kohli, G. S., Sharma, A., and Goel, H. (1989). Serum enzymes in head and neck cancer. IV: 5-nucleotidase. J. Laryngol. Otol. 103, 200-202. doi:10.1017/s00222151001084362538528

Leclerc, B. G., Charlebois, R., Chouinard, G., Allard, B., Pommey, S., Saad, F., et al. (2016). CD73 expression is an independent prognostic factor in prostate cancer. Clin. Cancer Res. 22, 158-166. doi:10.1158/1078-0432.ccr-15-118126253870

Lehto, M. T., and Sharom, F. J. (1998). Release of the glycosylphosphatidylinositolanchored enzyme ecto- $5^{\prime}$-nucleotidase by phospholipase C: catalytic activation and modulation by the lipid bilayer. Biochem. J. 332 (Pt 1), 101-109. doi:10. $1042 / \mathrm{bj} 3320101$

Loi, S., Pommey, S., Haibe-Kains, B., Beavis, P. A., Darcy, P. K., Smyth, M. J., et al. (2013). CD73 promotes anthracycline resistance and poor prognosis in triple negative breast cancer. Proc. Natl. Acad. Sci. U.S.A. 110, 11091-11096. doi:10. 1073/pnas.1222251110

Lu, X.-X., Chen, Y.-T., Feng, B., Mao, X.-B., Yu, B., and Chu, X.-Y. (2013). Expression and clinical significance of $\mathrm{CD} 73$ and hypoxia-inducible factor-1 $\alpha$ in gastric carcinoma. World J. Gastroenterol. 19, 1912-1918. doi:10.3748/wjg. v19.112.1912

Ludwig, N., Yerneni, S. S., Azambuja, J. H., Gillespie, D. G., Menshikova, E. V., Jackson, E. K., et al. (2020). Tumor-derived exosomes promote angiogenesis via adenosine A2B receptor signaling. Angiogenesis 23, 599-610. doi:10.1007/ s10456-020-09728-8

Ludwig, S., Floros, T., Theodoraki, M.-N., Hong, C.-S., Jackson, E. K., Lang, S., et al. (2017). Suppression of lymphocyte functions by plasma exosomes correlates with disease activity in patients with head and neck cancer. Clin. Cancer Res. 23 (16), 4843-4854. doi:10.1158/1078-0432.ccr-16-281928400428

Mandapathil, M., Boduc, M., Netzer, C., Güldner, C., Roessler, M., WallicekDworschak, U., et al. (2018). CD73 expression in lymph node metastases in patients with head and neck cancer. Acta Otolaryngol. 138, 180-184. doi:10. 1080/00016489.2017.1378436

Messaoudi, N., Cousineau, I., Arslanian, E., Henault, D., Stephen, D., Vandenbroucke-Menu, F., et al. (2020). Prognostic value of CD73 expression in resected colorectal cancer liver metastasis. OncoImmunology 9 1746138. doi:10.1080/2162402x.2020.1746138

Monteiro, I., Vigano, S., Faouzi, M., Treilleux, I., Michielin, O., Ménétrier-Caux, C., et al. (2018). CD73 expression and clinical significance in human metastatic melanoma. Oncotarget 9, 26659-26669. doi:10.18632/ oncotarget. 25426

Morello, S., Capone, M., Sorrentino, C., Giannarelli, D., Madonna, G., Mallardo, D., et al. (2017). Soluble CD73 as biomarker in patients with metastatic melanoma patients treated with nivolumab. J. Transl. Med. 15, 244. doi:10. 1186/s12967-017-1348-8

Muller, L., Hong, C.-S., Stolz, D. B., Watkins, S. C., and Whiteside, T. L. (2014). Isolation of biologically-active exosomes from human plasma. J. Immunol. Methods 411, 55-65. doi:10.1016/j.jim.2014.06.007

Neo, S. Y., Yang, Y., Record, J., Ma, R., Chen, X., Chen, Z., et al. (2020). CD73 immune checkpoint defines regulatory NK cells within the tumor microenvironment. J. Clin. Invest. 130, 1185-1198. doi:10.1172/jci128895

Reinhardt, J., Landsberg, J., Schmid-Burgk, J. L., Ramis, B. B., Bald, T., Glodde, N., et al. (2017). MAPK signaling and inflammation link melanoma phenotype switching to induction of CD73 during immunotherapy. Cancer Res. 77, 4697-4709. doi:10.1158/0008-5472.can-17-0395

Ren, Z.-H., Lin, C.-Z., Cao, W., Yang, R., Lu, W., Liu, Z.-Q., et al. (2016). CD73 is associated with poor prognosis in HNSCC. Oncotarget 7, 61690-61702. doi:10. 18632/oncotarget.11435

Schäkel, L., Schmies, C. C., Idris, R. M., Luo, X., Lee, S. Y., Lopez, V., et al. (2020). Nucleotide analog ARL67156 as a lead structure for the development of CD39 and dual CD39/CD73 ectonucleotidase inhibitors. Front. Pharmacol. 11, 1294. doi:10.3389/fphar.2020.01294

Schuler, P. J., Saze, Z., Hong, C.-S., Muller, L., Gillespie, D. G., Cheng, D., et al. (2014). Human $\mathrm{CD}^{+} \mathrm{CD} 9^{+}$regulatory $\mathrm{T}$ cells produce adenosine upon coexpression of surface $\mathrm{CD} 73$ or contact with $\mathrm{CD} 73^{+}$exosomes or $\mathrm{CD}^{+} 3^{+}$cells. Clin. Exp. Immunol. 177, 531-543. doi:10.1111/cei.12354

Sorrentino, R., Pinto, A., and Morello, S. (2013). The adenosinergic system in cancer: Key therapeutic target. Oncoimmunology. 2 (1), e22448. doi:10.4161/ onci.22448

Theodoraki, M.-N., Hoffmann, T. K., Jackson, E. K., and Whiteside, T. L. (2018). Exosomes in HNSCC plasma as surrogate markers of tumour progression and immune competence. Clin. Exp. Immunol. 194, 67-78. doi:10.1111/cei.13157

Théry, C., Witwer, K. W., Aikawa, E., Alcaraz, M. J., Anderson, J. D., Andriantsitohaina, R., et al. (2018). Minimal information for studies of extracellular vesicles 2018 (MISEV2018): a position statement of the International Society for Extracellular Vesicles and update of the MISEV2014 guidelines. J. Extracell. Vesicles 7, 1535750. doi:10.1080/20013078.2018.1461450

Thompson, E. A., and Powell, J. D. (2020). Inhibition of the adenosine pathway to potentiate cancer immunotherapy: potential for combinatorial approaches. Аnnu. Rev. Med. 72, 6.1-6.18. doi:10.1146/annurev-med060619-023155

Thompson, L. F., Ruedi, J. M., and Low, M. G. (1987). Purification of 5'nucleotidase from human placenta after release from plasma membranes by phosphatidylinositol-specific phospholipase C. Biochem. Biophys. Res. Commun. 145, 118-125. doi:10.1016/0006-291x(87)91295-2

Turcotte, M., Allard, D., Mittal, D., Bareche, Y., Buisseret, L., José, V., et al. (2017). CD73 promotes resistance to HER2/ErbB2 antibody therapy. Cancer Res. 77, 5652-5663. doi:10.1158/0008-5472.can-17-0707

Turcotte, M., Spring, K., Pommey, S., Chouinard, G., Cousineau, I., George, J., et al. (2015). CD73 is associated with poor prognosis in high-grade serous ovarian cancer. Cancer Res. 75, 4494-4503. doi:10.1158/0008-5472.can-14-3569

Vijayan, D., Young, A., Teng, M. W. L., and Smyth, M. J. (2017). Targeting immunosuppressive adenosine in cancer. Nat. Rev. Cancer 17, 709-724. doi:10. $1038 /$ nrc. 2017.86

Wang, B., Wang, D., Zhu, Z., Wang, W., Zhang, X., Tang, F., et al. (2016). The role of extracellular-5' ${ }^{\prime}$-nucleotidase/CD73 in glioma peritumoural brain edema. Neurol. Sci. 37, 603-611. doi:10.1007/s10072-016-2510-4

Wang, X., Zhang, T., Song, Z., Li, L., Zhang, X., Liu, J., et al. (2019). Tumor CD73/ $\mathrm{A} 2 \mathrm{aR}$ adenosine immunosuppressive axis and tumor-infiltrating lymphocytes in diffuse large B-cell lymphoma: correlations with clinicopathological characteristics and clinical outcome. Int. J. Cancer 145, 1414-1422. doi:10. $1002 /$ ijc. 32144 
Wennerberg, E., Spada, S., Rudqvist, N.-P., Lhuillier, C., Gruber, S., Chen, Q., et al. (2020). CD73 blockade promotes dendritic cell infiltration of irradiated tumors and tumor rejection. Cancer Immunol. Res. 8 (4), 465-478. doi:10.1158/23266066.cir-19-0449

Wettstein, M. S., Buser, L., Hermanns, T., Roudnicky, F., Eberli, D., Baumeister, P., et al. (2015). CD73 predicts favorable prognosis in patients with nonmuscleinvasive urothelial bladder cancer. Dis. Markers 2015, 785461. doi:10.1155/ 2015/785461

Wu, X.-R., He, X.-S., Chen, Y.-F., Yuan, R.-X., Zeng, Y., Lian, L., et al. (2012). High expression of CD73 as a poor prognostic biomarker in human colorectal cancer. J. Surg. Oncol. 106, 130-137. doi:10.1002/jso.23056

Yegutkin, G. G. (2008). Nucleotide- and nucleoside-converting ectoenzymes: important modulators of purinergic signalling cascade. Biochim. Biophys. Acta Mol. Cell Res. 1783, 673-694. doi:10.1016/j.bbamcr.2008.01.024

Yu, M., Guo, G., Huang, L., Deng, L., Chang, C.-S., Achyut, B. R., et al. (2020). CD73 on cancer-associated fibroblasts enhanced by the A2B-mediated feedforward circuit enforces an immune checkpoint. Nat. Commun. 11, 515. doi:10.1038/s41467-019-14060-x
Zhang, F., Li, R., Yang, Y., Shi, C., Shen, Y., Lu, C., et al. (2019). Specific decrease in B-Cell-Derived extracellular vesicles enhances post-chemotherapeutic CD8 ${ }^{+}$ $\mathrm{T}$ cell responses. Immunity 50, 738-750.e7. doi:10.1016/j.immuni.2019.01.010 Zimmermann, H., Zebisch, M., and Sträter, N. (2012). Cellular function and molecular structure of ecto-nucleotidases. Purinergic Signal. 8, 437-502. doi:10. $1007 /$ s11302-012-9309-4

Conflict of Interest: The authors declare that the research was conducted in the absence of any commercial or financial relationships that could be construed as a potential conflict of interest.

Copyright (C) 2020 Turiello, Pinto and Morello. This is an open-access article distributed under the terms of the Creative Commons Attribution License (CC $B Y)$. The use, distribution or reproduction in other forums is permitted, provided the original author(s) and the copyright owner(s) are credited and that the original publication in this journal is cited, in accordance with accepted academic practice. No use, distribution or reproduction is permitted which does not comply with these terms. 